\title{
Validation of the Spanish version of the Goodman score in total hip arthroplasty
}

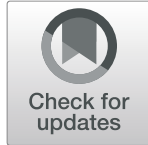

Julián Brañes ${ }^{1,2^{*}}\left(\mathbb{D}\right.$, Maximiliano Barahona ${ }^{2}$ (D), Sebastián Carvajal ${ }^{1}$, Rodrigo Wulf ${ }^{2}$ and Cristián Barrientos ${ }^{1,2,3}$ (D)

\begin{abstract}
Purpose: Currently, patient-reported outcome measures (PROMs) are the standard instruments used to compare arthroplasty results. Goodman et al. recently published a well-constructed scale with excellent psychometric properties that can be quickly administered. The main objective of our study was to translate, culturally adapt, and validate a Spanish version of the Goodman questionnaire in patients who underwent total hip arthroplasty (THA).

Methods: The original Goodman scale was translated into Spanish and cross-culturally adapted. Then, the data from this version were tested for psychometric quality. We designed a cross-sectional study for data collection. This study enrolled 2 institutions. Patients who underwent hip replacement due to primary osteoarthritis secondary to dysplasia between 1 January 2018 and 31 December 2019 were included. A total of 153 patients were contacted twice to record the Goodman and Oxford hip scales (OHS) to assess the validity of the questionnaire. Reliability was tested using the Cronbach's alpha, Concordance using 3 test: intraclass correlation coefficient (ICC), Lin's concordance correlation coefficient (CCC), and the Bradley-Blackwood $F$ test. The spearman correlation was used to asses correlation between the OHS and the Spanish-adapted Goodman scale.

Results: The overall satisfaction after THA was reported to be "very satisfied" by 137 patients (75\%), and only 14 patients reported some degree of dissatisfaction (6\%). The improvement in quality of life was reported to be "more than I ever dreamed possible" by $41 \%$ patients. Cronbach's alpha was acceptable, reaching a coefficient of 0.95 (95\% confidence interval, $0.82-1$ ). No statistical difference ( $t$ test, $p=0.55$ ) was found in the original version, with great internal validity. Test re-test concordance was optimal among the 3 tests used. A moderate correlation was found between the OHS and the Spanish-adapted Goodman scale.
\end{abstract}

Conclusion: The Spanish version of the Goodman questionnaire in THA is a reliable, consistent, and feasible scale to evaluate patient satisfaction and improvement in the quality of life in Spanish speakers.

Keywords: Total hip arthroplasty, PROMs, Cross-cultural adaptation, Translation, Satisfaction, Validation studies

\footnotetext{
*Correspondence: julianbranes@gmail.com

'Orthopaedic Department, Hospital Clinico San José, 999 Santos Dumont

Street, 3rd Floor, Office 351, 8380456 Santiago, Independencia, Chile

${ }^{2}$ Orthopaedic Department, Hospital Clinico Universidad de Chile, Santiago,

Chile

Full list of author information is available at the end of the article
}

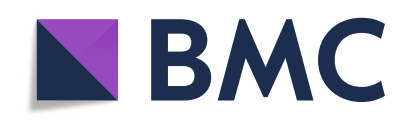

(c) The Author(s). 2021 Open Access This article is licensed under a Creative Commons Attribution 4.0 International License, which permits use, sharing, adaptation, distribution and reproduction in any medium or format, as long as you give appropriate credit to the original author(s) and the source, provide a link to the Creative Commons licence, and indicate if changes were made. The images or other third party material in this article are included in the article's Creative Commons licence, unless indicated otherwise in a credit line to the material. If material is not included in the article's Creative Commons licence and your intended use is not permitted by statutory regulation or exceeds the permitted use, you will need to obtain permission directly from the copyright holder. To view a copy of this licence, visit http://creativecommons.org/licenses/by/4.0/ The Creative Commons Public Domain Dedication waiver (http://creativecommons.org/publicdomain/zero/1.0/) applies to the data made available in this article, unless otherwise stated in a credit line to the data. 


\section{Introduction}

Total hip arthroplasty (THA) is the gold standard in the treatment of severe hip osteoarthritis with intractable pain. THA improves the quality of life to such a degree that it was labeled as the surgery of the twentieth century [1].

Nevertheless, there is still room for further improvement. It is essential to develop instruments to compare results between different surgical approaches, prosthetic models, type of hospitalization, and pain management, to name a few $[2,3]$. The current focus is being placed on patient-reported outcome measures (PROMs), which is the standard to make these comparisons. A perfect PROM has to be reliable, accessible, validated, responsive to change, and measure clinical results with minimal administrative burden [4]. The use of PROMS in the literature has markedly increased in the past decade, with the Harris hip score being the most frequently used in THA [5]. Different countries have developed national registries using PROMS to evaluate their outcomes, with language and cultural interpretations being limitations to their use and extrapolating the results $[6,7]$

Goodman et al. [8] recently published a wellconstructed scale with excellent psychometric properties that can be quickly administered-only 5 questions-and that allows estimation of patient satisfaction with THA. Although the score achieves a moderate correlation with pain and function, it has different dimensions; therefore, it should be evaluated independently. We believe that assessing patient satisfaction is crucial in THA; however, this scale is not in Spanish. According to the data of 2020, about 489 million people were native Spanish speakers, and 585 million (7.5\% of the world population) speak Spanish [9]. Hence, it is of immense value to translate and perform a cultural adaptation of the new assessment tools to Spanish to extend their application.

The main objective of our study was to translate, culturally adapt, and validate a Spanish version of the Goodman questionnaire in patients who underwent total hip arthroplasty. We hypothesize that systematic translation and adaptation will lead to the development of a questionnaire with equal reliability and consistency as that of the English version.

\section{Methods}

This study was designed in 2 phases. First, the original Goodman scale was translated into Spanish and crossculturally adapted. Following the implementation of the Spanish version, the psychometric quality of the data was tested. This study was approved by the ethics review board.

The Goodman satisfaction scale consists of 2 items: the first assesses satisfaction through 4 questions, each rated on a 5-point Likert scale. The satisfaction summary score corresponds to the non-weighted average of the 4 questions, which correspond to $100,75,50$, 25 , and 0 according to the nominal response (for example, "very satisfied" corresponds to score 100 and "very dissatisfied" to 0). The second item aimed to evaluate the quality of life using a single question. This scale is valid and reliable, with high internal consistency and feasibility, and can be used postoperatively to assess the impact of THA [7].

The translation and cross-cultural adaptations were performed according to the recommended methodology through the following step s[10]: first, a forward translation to Spanish was performed by 2 translators whose mother tongue was Spanish and fluent in English. A back-translation to English was carried out by 2 translators whose mother tongue was English and fluent in Spanish. A consensus meeting including 3 experts in THA, translators, and medical students compared the original English version and the back-translated version for consistency. In the same session, the clinicallinguistic issues in the Spanish-translated version were addressed. Then, the final version was tested for the level of understanding on 30 randomly selected patients who underwent THA.

We designed a cross-sectional study for data collection, and 2 institutions were enrolled: a university and a public hospital. Both centers had access to the same type and brands of prostheses to perform surgery, and surgeons had similar levels of training; 2 of the surgeons work in both centers, and the orthopaedic departments of both centers conducted joint academic activities regularly and shared a training program for fellow hip surgeons.

Patients were included if they were above 18 years of age and underwent hip replacement due to primary osteoarthritis secondary to dysplasia between 1 January 2018 and 31 December 2019. In all cases, the posterior hip approach and a primary non-constrained prosthesis were used (Corail $^{\odot}$ uncemented hip stem, Pinnacle ${ }^{\odot}$ uncemented cup: DePuy Synthes, Warsaw, IN). All hip fractures, hip revisions, infections, and bilateral cases were excluded, as were patients with language or mental impairment.

A total of 520 patients were eligible for assessment. The medical records were screened to collect sociodemographic and clinical data, including sex, age, date of surgery, surgery protocol, phone, and e-mail.

A total of 300 patients met the selection criteria, and attempts to contact them were initiated in June 2020; therefore, all patients had at least 1 year of follow-up after THA. Of them, 210 patients were successfully contacted by phone or mail, provided digital written or verbal informed consent to be enrolled in the study, and responded to the Goodman scale and the Oxford hip 
scale (OHS). The OHS is a globally accepted scale which was validated in Spanish [11], consisting of 12 questions to evaluate patients' functionality, and ranges from 12 to 60 . The lower the score, the better the outcome. The OHS was used to assess the validity of the adapted Goodman scale [12]. The scale was sent again 14 days after the first response was received. A total of 153 patients returned the second round of answers for analysis (Fig. 1).

Cronbach's alpha was estimated for reliability (internal consistency) analysis. A coefficient greater than 0.75, was considered acceptable [13]. The alpha coefficient was assumed to be normally distributed, and $t$ test was used to compare the Cronbach's alpha between this study and that performed by Goodman et al. [8]. In addition, factor analysis was performed, and the factors were maintained if the eigenvalue was above 1 .

The test-retest was assessed by comparing the first response with the answers obtained 14 days later. The intraclass correlation coefficient (ICC), Lin's concordance correlation coefficient (CCC), and the Bradley-Blackwood F test were used. An ICC and CCC over 0.75 , were considered acceptable; meanwhile, a probability over 0.15 , was deemed acceptable to validate the null hypothesis of concordance in the Bradley-Blackwood $F$ test [14].

Finally, Spearman correlation (rho) test was conducted using the OHS score to validate the Spanish-adapted Goodman scale. An absolute rho above 0.6, was interpreted as good correlation [15].

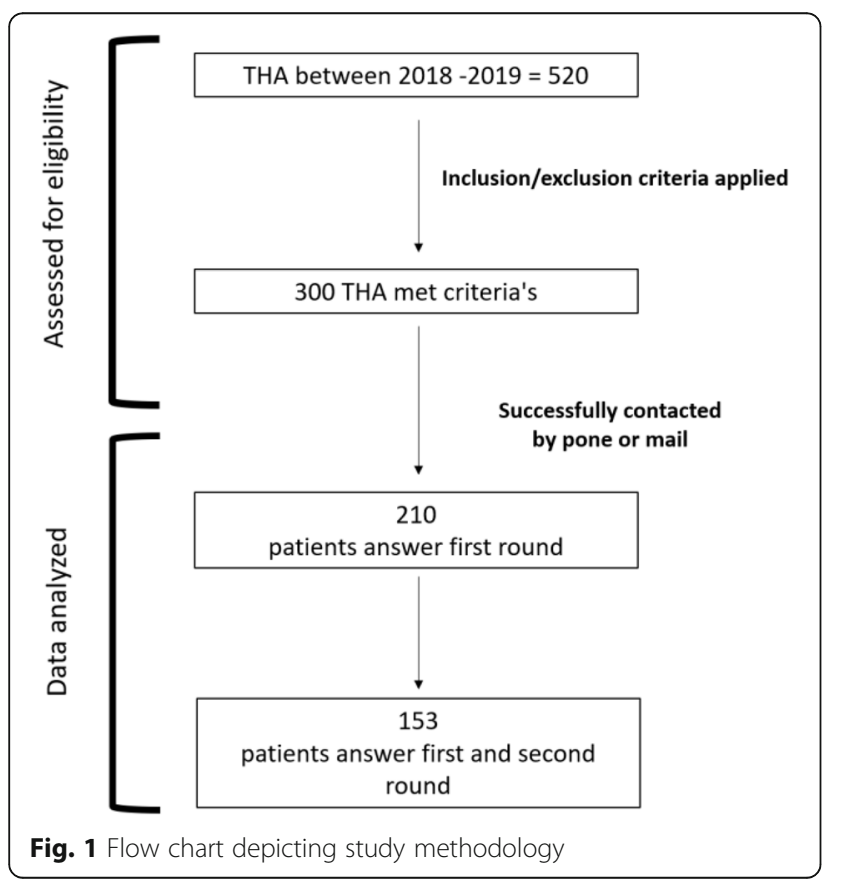

\section{Results}

A total of 210 patients answer the first round of questions. The median age was 68 years old (range, 23 to 89; interquartile range, 59 to 74 ), and 136 patients were female (64.76\%). The median score of OHS and the Spanish-adapted Goodman scale is described in Table 1.

The overall satisfaction after THA was reported to be "very satisfied" by 137 patients (75\%), and only 14 patients reported some degree of dissatisfaction (6\%) (Table 1). Table 1 shows the satisfaction summary score of the Spanish-adapted Goodman and the OHS scores obtained in both rounds. The improvement in quality of life was reported to be "more than I ever dreamed possible" by 81 patients (41\%), "great improvement" by 89 patients (42\%), "moderate improvement" by 25 (12\%), "a little improvement" by 7 patients (3\%), "no improvement" by 2 patients (1\%) and "worse quality of life" by only 6 patients (3\%) (Table 2).

A total of 153 patients who underwent total hip replacement were successfully contacted twice to assess the adapted Goodman scale. The median age was 67 years (range, 23-75 years; interquartile range, 58-75 years), and 106 patients were women (70.7\%) (Table 1). No major complications were observed at the end of follow-up.

The Cronbach's alpha was acceptable, reaching a coefficient of 0.95 (95\% confidence interval, $0.82-1$ ). No statistical difference ( $t$ test, $p=0.55)$ was found with the original 0.92 alpha coefficient reported by Goodman et al. [6]. The factorial analysis showed great internal validity as it isolated only 1 factor with an eigenvalue of 3.33 (Fig. 2). This shows that 1 answer accounted for $90 \%$ of the score, reinforcing that this cultural adaptation achieved a high level of internal consistency.

Test re-test concordance was achieved among the 3 tests. The ICC was 0.87 (95\% confidence interval, 0.840.91), CCC was 0.87 (95\% confidence interval, 0.840.91), and the Bradley-Blackwood test reached a probability of 0.1 , meaning that all 3 concordance assessments were optimal [16].

Table 1 Satisfaction summary score of the Spanish adaptation of the Goodman scale and the Oxford hip scale in rounds 1 and 2

\begin{tabular}{lll}
\hline & S-A Goodman satisfaction & OHS \\
\hline Round 1 $(n)$ & 210 & 210 \\
- Median (range) & $100(0$ to 100$)$ & 19 (12 to 56) \\
- IQR & 81.3 to 100 & 15 to 33 \\
Round 2 ( $n)$ & 153 & 153 \\
- Median (range) & $100(0$ to 100$)$ & $19(12$ to 53$)$ \\
-IQR & 87.5 to 100 & 15 to 28 \\
\hline
\end{tabular}

Abbreviations: S-A Spanish-adapted, IQR interquartile range 
Table 2 Summary of questions on patient satisfaction dimension of the Spanish adaptation of the Goodman scale in round 1

\begin{tabular}{lllll}
\hline Satisfaction & Pain relief & Housework or yard work & Recreational activities & Overall \\
\hline Very satisfied & $160(76 \%)$ & $136(65 \%)$ & $124(59 \%)$ & $157(75 \%)$ \\
Somewhat satisfied & $30(14 \%)$ & $48(23 \%)$ & $53(25 \%)$ & $31(15 \%)$ \\
Neither satisfied nor dissatisfied & $5(2 \%)$ & $9(4 \%)$ & $17(8 \%)$ & $8(4 \%)$ \\
Somewhat dissatisfied & $10(5 \%)$ & $7(3 \%)$ & $8(4 \%)$ & $8(4 \%)$ \\
Very dissatisfied & $5(2 \%)$ & $10(5 \%)$ & $8(4 \%)$ & $6(3 \%)$ \\
\hline
\end{tabular}

The Spearman correlation showed a moderate correlation between the OHS and the Spanish-adapted Goodman scale. In the first round, rho was -0.64 for patient satisfaction and 0.66 for change in quality of life. Meanwhile, in the second round, the rho estimated was -0.63 in patient satisfaction and 0.61 to improve the quality of life.

\section{Discussion}

This study describes a reliable and consistent Spanish adaptation of the Goodman scale, which evaluated patient satisfaction and quality of life after THA in Spanish speakers. Before using a recognized instrument to assess patients' reported outcomes, it is imperative to perform a systematic translation and cultural adaptation [17].

Currently, PROMs are the most commonly used to compare surgical procedures in orthopaedic literature $[18,19]$. PROMs have recently been used in national registries and could be helpful in decision-making in total joint arthroplasty and as an early indicator in implant failure [20, 21]. However, it is crucial to limit their use to evaluate aspects for which the scale was constructed for and to interpret their results according to their psychometric qualities [22, 23]. Moreover, Gagnier et al. [2] reported that no single PROM can evaluate all dimensions and have the required psychometric

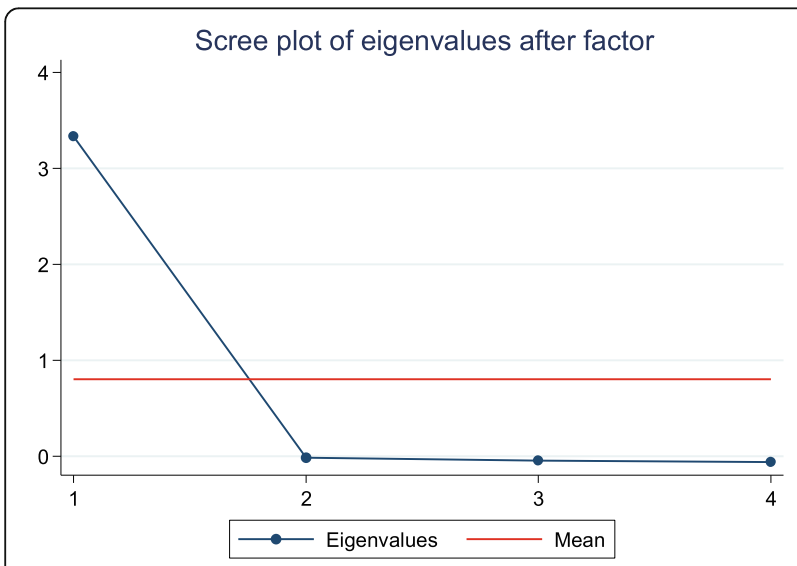

Fig. 2 Screen plot of eigenvalues after factor analysis. Only 1 factor reached an eigenvalue above 1 . This factor explains $90 \%$ of the answers properties. This highlights the contribution of this work, adding feasibility and ease of management with proven psychometric properties to evaluate patient satisfaction and quality of life. This dimension was not addressed in the PROMs available in Spanish. Other characteristics of this scale are that it is available for free and can be selfadministered on paper, by phone, or e-mail.

Patient satisfaction is a goal that every hip surgeon yearns for his patient and accurately measuring it is a keystone. Despite its relevance, a lack of instruments to assess this critical dimension has been reported [24]. Goodman et al. [8] reported in 2020 this promising tool, which we consider is important to be available in Spanish, given the number of Spanish speakers worldwide [9]. We did not find drawbacks during translation and cross-cultural adaptation; therefore, we encourage other surgeons interested in adapting this scale to their language.

Additionally, we report $86 \%$ of scored 75 points in the satisfaction dimension, and $88 \%$ said that their quality of life had a "great improvement" or "more than I ever dreamed possible," which is consistent with the great experience reported by patients after THA [25] and to the original report of Goodman et al. [8].

A concern in this study is that no strong validation has been reported for OHS. The correlation with the OHS was good, as expected, because the OHS aimed to evaluate pain and function, which is not necessarily related to patient satisfaction or the change in quality of life that the Goodman scale seeks to assess. Moreover, Yeo et al. [26] recently reported that OHS is not a good PROM for evaluating satisfaction after THA. Nevertheless, the OHS is widely used, available in Spanish, and its psychometric properties have been rigorously tested [11, 27]. Therefore, in the absence of another Spanish test that addresses patient satisfaction, it seemed appropriate, and obtaining a reasonably good correlation should not question the validity of the score.

A limitation of this study is that a high percentage of patients could not complete the 2 rounds of answers. An explanation is that a portion of our population has digital illiteracy, limiting their accountability to answer e-mails. Another limitation is that no clinical outcomes were measured, such as range of motion. This study was carried out during the corona virus disease-2019 
outbreak, making it unpropped to cite them in person; nevertheless, the original article did not measure clinical parameters. Additionally, this study has only a minimum of 1-year follow-up, but this should not affect the psychometric properties, even though an extensive followup could be necessary for future studies.

\section{Conclusions}

The Spanish version of the Goodman questionnaire in THA is a reliable, consistent, and feasible scale to evaluate patient satisfaction and improve the quality of life of Spanish speakers. The excellent psychometric properties reported in this study are comparable to those of the original English version.

\section{Abbreviations}

PROMs: Patient-reported outcome measures; THA: Total hip arthroplasty; OHS: Oxford hip scales; ICC: Intraclass correlation coefficient; CCC: Lin's concordance correlation coefficient

\section{Supplementary Information}

The online version contains supplementary material available at https://doi. org/10.1186/s13018-021-02653-6

Additional file 1. Adaptación cultural al español de la encuesta de Goodman.pdf. Cuestionario de Goodman en español. Spanish version of the Goodman questionnaire and instructions for the patients to complete it.

\section{Acknowledgements}

We thank Dr. Susan Goodman, MD, for authorizing the use of her questionnaire, and for critically reviewing and commenting on this article.

\section{Authors' contributions}

SC and JB collected data and wrote the manuscript. MB analyzed data. RW helped to draft the manuscript. CB made the final modifications. All authors agree to be accountable for all aspects of the work. All authors read, reviewed, and approved the final manuscript.

\section{Funding}

This research received no specific grant from any funding agency in the public, commercial, or not-for-profit sectors.

\section{Availability of data and materials}

All data generated or analyzed during this study are included in this published article and its supplementary information files.

\section{Declarations}

\section{Ethics approval and consent to participate}

The Hospital San José Ethical Committee approved the study and appropriate written consents were obtained from all patients

\section{Consent for publication}

Not applicable.

\section{Competing interests}

The authors declare that they have no competing interests.

\section{Author details}

'Orthopaedic Department, Hospital Clinico San José, 999 Santos Dumont Street, 3rd Floor, Office 351, 8380456 Santiago, Independencia, Chile. ${ }^{2}$ Orthopaedic Department, Hospital Clinico Universidad de Chile, Santiago, Chile. ${ }^{3}$ Orthopaedic Department, Clinica Santa María, Santiago, Chile.
Received: 29 June 2021 Accepted: 5 August 2021

Published online: 20 August 2021

\section{References}

1. Learmonth ID, Young C, Rorabeck C. The operation of the century: total hip replacement. Lancet. 2007;370(9597):1508-19. https://doi.org/10.1016/S01406736(07)60457-7.

2. Gagnier JJ, Huang H, Mullins M, Marinac-Dabić D, Ghambaryan A, Eloff B, et al. Measurement properties of patient-reported outcome measures used in patients undergoing total hip arthroplasty: a systematic review. JBJS Rev. 2018;6(1):e2. https://doi.org/10.2106/JBJS.RWW.17.00038

3. Longo UG, Ciuffreda M, Candela V, Berton A, Maffulli N, Denaro V. Hip scores: a current concept review. Br Med Bull. 2019;131(1):81-96. https://doi. org/10.1093/bmb/ldz026.

4. Collins NJ, Roos EM. Patient-reported outcomes for total hip and knee arthroplasty: commonly used instruments and attributes of a "good" measure. Clin Geriatr Med. 2012;28(3):367-94. https://doi.org/10.1016/j.cger.2 012.05.007.

5. Siljander MP, McQuivey KS, Fahs AM, et al. Current trends in patientreported outcome measures in total joint arthroplasty: a study of 4 major orthopaedic journals. J Arthroplasty. 2018;33(11):3416-21. https://doi.org/1 0.1016/j.arth.2018.06.034

6. Behrend H, Giesinger K, Giesinger JM, et al. The "forgotten joint" as the ultimate goal in joint arthroplasty: validation of a new patient-reported outcome measure. J Arthroplasty. 2012;27:430-436. e1.

7. Kang S. Assessing responsiveness of the EQ-5D-3L, the Oxford Hip Score, and the Oxford Knee Score in the NHS patient-reported outcome measures. J Orthop Surg Res. 2021;16(1):115 J Orthop Surg Res. 2021;16(1):18. published correction appears in.

8. Goodman SM, Mehta BY, Kahlenberg CA, et al. Assessment of a satisfaction measure for use after primary total joint arthroplasty. J Arthroplasty. 2020;35: 1792-1799. e4.

9. Instituto Cervantes. Reporte anual "EL ESPAÑOL: UNA LENGUA VIVA". 2020

10. Mokkink LB, Terwee CB, Patrick DL, Alonso J, Stratford PW, Knol DL, et al. The COSMIN study reached international consensus on taxonomy, terminology, and definitions of measurement properties for health-related patient-reported outcomes. J Clin Epidemiol. 2010;63(7):737-45. https://doi. org/10.1016/j.jclinepi.2010.02.006.

11. Martín-Fernández J, Gray-Laymón P, Molina-Siguero A, Martínez-Martín J, García-Maroto R, García-Sánchez I, et al. Cross-cultural adaptation and validation of the Spanish version of the Oxford Hip Score in patients with hip osteoarthritis. BMC Musculoskelet Disord. 2017;18(1):205. https://doi. org/10.1186/s12891-017-1568-3.

12. Sánchez R, Echeverry J. Validación de escalas de medición en salud [Validating scales used for measuring factors in medicine]. Rev Salud Publica (Bogota). 2004;6:302-18

13. Wang $\mathrm{D}$, Jones MH, Khair MM, Miniaci A. Patient-reported outcome measures for the knee. J Knee Surg. 2010;23(03):137-51. https://doi.org/10.1 055/s-0030-1268691

14. Lin LI. A concordance correlation coefficient to evaluate reproducibility. Biometrics. 1989:45(1):255-68. https://doi.org/10.2307/2532051.

15. Zar JH. Spearman rank correlation. Encyclopedia of Biostatistics, vol. 7) Online ISBN: 9780470011812|: Wiley; 2005. https://doi.org/10.1002/0470011 815.

16. Bland JM, Altman DG. Statistical methods for assessing agreement between two methods of clinical measurement. Lancet. 1986;1(8476):307-10.

17. Arias-de la Torre J, Puigdomenech E, Valderas JM, Evans JP, Martín V, Molina AJ, et al. Availability of specific tools to assess patient reported outcomes in hip arthroplasty in Spain. Identifying the best candidates to incorporate in an arthroplasty register. A systematic review and standardised assessment. PloS one. 2019;14:e0214746.

18. Brook EM, Glerum KM, Higgins LD, et al. Implementing patient-reported outcome measures in your practice: pearls and pitfalls. Am J Orthop (Belle Mead NJ). 2017;46:273-8

19. Hamilton DF, Giesinger JM, Giesinger K. It is merely subjective opinion that patient-reported outcome measures are not objective tools. Bone Joint Res. 2017:6(12):665-6. https://doi.org/10.1302/2046-3758.612.BJR-2017-0347.

20. Rolfson O, Eresian Chenok K, Bohm E, et al. Patient-reported outcome measures in arthroplasty registries. Acta Orthop. 2016;87 Suppl 1(Suppl 1):38. https://doi.org/10.1080/17453674.2016.1181815. 
21. Fidai MS, Saltzman BM, Meta F, Lizzio VA, Stephens JP, Bozic KJ, et al. Patient-reported outcomes measurement information system and legacy patient-reported outcome measures in the field of orthopaedics: a systematic review. Arthroscopy. 2018;34(2):605-14. https://doi.org/10.1016/j.a rthro.2017.07.030.

22. Snell DL, Dunn JA, Jerram KAS, Hsieh CJ, DeJong G, Hooper GJ. Associations between comorbidity and quality of life outcomes after total joint replacement. Qual Life Res. 2021;30(1):137-44. https://doi.org/10.1007/s1113 6-020-02610-6.

23. Alshehri F, Alarabi A, Alharthi M, Alanazi T, Alohali A, Alsaleem M. Use of patient-reported outcome measures (PROMs) by orthopedic surgeons in Saudi Arabia. J Orthop Surg Res. 2020;15(1):598. https://doi.org/10.1186/s13 018-020-02135-1.

24. Kahlenberg CA, Nwachukwu BU, McLawhorn AS, et al. Patient satisfaction after total knee replacement: a systematic review. HSS J. 2018;14(2):192-201. https://doi.org/10.1007/s11420-018-9614-8.

25. Pivec R, Johnson AJ, Mears SC, et al. Hip arthroplasty. Lancet. 2012; 380(9855):1768-77. https://doi.org/10.1016/S0140-6736(12)60607-2.

26. Yeo MGH, Goh GS, Chen JY, Lo NN, Yeo SJ, Liow MHL. Are Oxford Hip score and Western Ontario and McMaster Universities Osteoarthritis index useful predictors of clinical meaningful improvement and satisfaction after total hip arthroplasty? J Arthroplasty. 2020;35(9):2458-64. https://doi.org/10.1016/ j.arth.2020.04.034.

27. Kalairajah Y, Azurza K, Hulme C, Molloy S, Drabu K. Health outcome measures in the evaluation of total hip arthroplasties-a comparison between the Harris hip score and the Oxford hip score. J Arthroplasty. 2005; 20(8):1037-41. https://doi.org/10.1016/j.arth.2005.04.017.

\section{Publisher's Note}

Springer Nature remains neutral with regard to jurisdictional claims in published maps and institutional affiliations.

Ready to submit your research? Choose BMC and benefit from:

- fast, convenient online submission

- thorough peer review by experienced researchers in your field

- rapid publication on acceptance

- support for research data, including large and complex data types

- gold Open Access which fosters wider collaboration and increased citations

- maximum visibility for your research: over $100 \mathrm{M}$ website views per year

At $\mathrm{BMC}$, research is always in progress.

Learn more biomedcentral.com/submissions 